\title{
PET-PROGRAMA DE EDUCAÇÃO TUTORIAL: ESTRUTURA E AÇÕES NAS CIDADES DE SÃO RAIMUNDO NONATO-PI, JUAZEIRO-BA E PETROLINA-PE
}

\author{
Marcelo de Maio Nascimento \\ Universidade Federal do Vale do São Francisco \\ marcelo.nascimento@univasf.edu.br \\ Celito Kestering \\ Universidade Federal do Vale do São Francisco \\ celito.kestering@univasf.edu.br
}

\author{
Sérgio Rodrigues Moreira \\ Universidade Federal do Vale do São Francisco \\ sergio.moreira@univasf.edu.br \\ Miriam Cleide Cavalcante de Amorim \\ Universidade Federal do Vale do São Francisco \\ miriam.cleide@univasf.edu.br
}

\begin{abstract}
Resumo
Este estudo apresenta os grupos PET Arqueologia, Biomecânica, Educação Física e Saneamento Ambiental, vinculados à Universidade Federal do Vale do São Francisco/UNIVASF, a qual possui a estrutura multicampi. Sendo assim, os grupos PET contribuem para o processo de interiorização da educação superior nos Estados de Pernambuco, Bahia e Piauí. Suas ações priorizam a indissociabilidade entre o ensino, a pesquisa e a extensão, qualificando 48 alunos bolsistas. $\mathrm{O}$ texto destaca as ações dos grupos durante o triênio, 2011-2013, apresentando objetivos, procedimentos metodológicos e principais resultados obtidos junto às comunidades com que operaram. Conclui-se que em três anos de trabalho, as equipes PET aprimoraram a formação acadêmica de um grupo significativo de discentes da UNIVASF, funcionando como mecanismo à aproximação do saber acadêmico à resolução de demandas sociais no âmbito da saúde e da preservação do patrimônio na região Nordeste do Brasil.
\end{abstract}

Palavras-chave: Programa de Educação Tutorial (PET). Interdisciplinaridade. Extensão. Ensino Superior.

\section{PET-TUTORIAL EDUCATION PROGRAM: STRUCTURE AND ACTIONS IN THE CITIES OF SÃO RAIMUNDO NONATO-PI, JUAZEIRO-BA AND PETROLINA-PE}

\begin{abstract}
This study presents the PET archeology groups, Biomechanics, Physical Education and Environmental Sanitation, linked to the Federal University of Vale do São Francisco/UNIVASF, which has the multicampi structure. Therefore, PET groups contribute to the process of internalization of higher education in the states of Pernambuco, Bahia and Piauí. His actions prioritize the inseparability of teaching, research and extension, qualifying 48 students fellows. The text highlights the actions of groups during the three-year period, 2011-2013, presenting objectives, methodological procedures and main results obtained to communities that have operated. We conclude that in three years of work, PET teams improved the academic background of a significant group of students of UNIVASF, functioning as a mechanism to align with the academic knowledge to solve social demands within the health and preservation of heritage in the region Northeast of Brazil.
\end{abstract}

Keywords: Tutorial Education Program (TEP). Interdisciplinarity. Extension. Higher Education.

\section{PET-EDUCACIÓN PROGRAMA TUTORIAL: ESTRUCTURA Y ACCIONES EN CIUDADES DE SÃO RAIMUNDO NONATO-PI, JUAZEIRO-BA Y PETROLINA-PE}

\section{Resumen}

Este estudio presenta los grupos de PET Arqueología, Biomecánica, Educación Física y el Saneamiento Ambiental, vinculados a la Universidad Federal del Vale do São Francisco/UNIVASF, que tiene la estructura multicampi. Por lo tanto, los grupos PET contribuyen al proceso de internalización de la educación superior en los estados de Pernambuco, Bahia y Piauí. Sus acciones priorizan la inseparabilidad de la enseñanza, investigación y extensión, calificando 48 estudiantes becados. El texto destaca las acciones de los grupos durante el período de tres años, 2011-2013, presentando los objetivos, los procedimientos metodológicos y resultados principales obtenidos a las comunidades que han operado. Llegamos a la 
conclusión de que en tres años de trabajo, los equipos PET mejoró la formación académica de un grupo significativo de estudiantes de UNIVASF, funcionando como un mecanismo para alinearse con el conocimiento académico para resolver las demandas sociales de la salud y la preservación del patrimonio de la región Brasil nororiental.

Palabras clave: Programa de Educación Tutorial (PET). La interdisciplinariedad. Extensión. Enseñanza superior. 
PET-Programa de educação tutorial: estrutura e ações nas cidades de São Raimundo Nonato-PI, Juazeiro-BA e petrolina-PE

\section{INTRODUÇÃO}

O Programa de Educação Tutorial (PET) consiste em equipes que buscam a indissociabilidade entre o Ensino, a Pesquisa e a Extensão, desenvolvendo ações direcionadas às demandas da região em que estão inseridos. Os grupos são formados por até doze estudantes, coordenados por um tutor, e todos vinculados a uma Instituição do Ensino Superior (IES). O PET foi criado no ano de 1979 sob a denominação de "Programa Especial de Treinamento". Inicialmente, esteve sob o encargo da Coordenação de Aperfeiçoamento de Pessoal de Nível Superior (CAPES). Desde 1999, sua gestão é de responsabilidade do Departamento de Modernização e Programas da Educação Superior (DEPEM), adjunto à Secretaria de Educação Superior do Ministério da Educação (MEC).

Segundo o Plano Nacional de Extensão (BRASIL, 2007, p. 85), “A Extensão é uma via de mão dupla, com trânsito assegurado à comunidade acadêmica que encontra, na sociedade, a oportunidade à elaboração da práxis de um conhecimento acadêmico". Isso significa dizer que a filosofia petiana incide em criar condições que possibilitem ao aluno vivenciar fatos, em geral, ausentes na estrutura curricular, aprimorando assim sua formação acadêmica. Dessa forma, ações petianas são impactantes à formação dos acadêmicos para o mercado de trabalho. Paralelo a isso, há de se considerar que as obras do PET viabilizam o empoderamento das comunidades com que as equipes atuam. Mediante as ações, os integrantes da comunidade são estimulados a refletir temas comuns, o que lhes auxilia na elaboração de mecanismos que possam amenizar ou solucionar problemas locais. Sendo assim, o programa apresenta-se como uma mão dupla, pois tanto contribui para o desenvolvimento de princípios de cidadania dos cidadãos, como dos petianos. A medida integra as diretrizes básicas do programa (MEC/DEPEM, 2006).

$\mathrm{Na}$ Universidade Federal do Vale do São Francisco/UNIVASF existem quatro grupos PET, são eles: PET- Arqueologia, PET-Biomecânica, PET-Educação Física e PET-Saneamento Ambiental. Os mesmos estão vinculados à Pró-Reitoria de Ensino (PROEN), cabendo ao Comitê Local de Acompanhamento e Avaliação (CLAA) a supervisão administrativa. A vigência do programa PET é de três anos. No entanto, o tutor pode estender seu exercício até seis anos. As equipes PET são compostas por acadêmicos na condição de bolsista e/ou voluntário, os quais são eleitos mediante processo seletivo, divulgado em Edital. Anualmente, os grupos recebem um financiamento do MEC-FNDE, a verba é destinada ao custeio de materiais de consumo, bem como à participação dos petianos em encontros acadêmicos.

O presente relato tem por escopo apresentar os quatro grupos PET da Universidade Federal do Vale do São Francisco/UNIVASF. Assim, será exibido a estrutura funcional das 
PET-Programa de educação tutorial: estrutura e ações nas cidades de São Raimundo Nonato-PI, Juazeiro-BA e petrolina-PE

equipes, objetivos, procedimentos metodológicos, enfatizando-se também os principais resultados e dificuldades encontradas, no período entre 2011-2013, no âmbito do Ensino, da Pesquisa e da Extensão.

\section{PET-ARQUEOLOGIA}

O PET-Arqueologia está sediado no Campus de São Raimundo Nonato, no Estado do Piauí. Este grupo dialoga com dois cursos da formação do bacharelado (Arqueologia e Preservação Patrimonial) e um de licenciatura (Ciências da Natureza). A equipe direciona suas atividades à valorização e à preservação patrimonial e arqueológica da região Sudeste do Piauí, fortalecendo assim a memória e a história local. Seus principais objetivos são:

I) Formar e informar discentes em sentido crítico para atuação junto à comunidade local;

II) Estimular a produção científica com foco na área da Arqueologia, no Campus UNIVASF/Serra da Capivara;

III) Incentivar práticas de releitura relativas à história do município de São Raimundo Nonato-PI, no período das comemorações do seu centenário.

\section{PROCEDIMENTOS METODOLÓGICOS}

A metodologia do PET-Arqueologia é marcada pelo aprender a fazer, fazendo diante dos desafios, consolidando assim processos à busca de soluções para os problemas que, por ventura, surjam no decorrer do tempo. Seus artifícios incidem em leituras dirigidas de artigos, monografias, dissertações e teses, com foco em conceitos e métodos da área da Arqueologia Histórica tradicional, incluindo contextos arqueológicos e históricos da região Sudeste do Piauí.

As atividades são coordenadas pelo tutor, recebendo contribuições das disciplinas de Arqueologia Histórica I-II e Métodos e Técnicas Arqueológicas III e IV. No período de 2011 2013, a ferramenta de trabalho eleita teve como princípio o ganho de saberes a partir da escuta dos personagens locais, os quais, habitualmente, não são/foram ouvidos pela historiografia oficial. Sendo assim, o PET-Arqueologia possibilitou a reconstrução de diferentes períodos históricos por intermédio do registro da epopeia dos ancestrais dos sujeitos vivos: índios, negros e portugueses que povoaram a região Sudeste do Piauí. O método utilizado incidiu na análise da realidade vestigial da cultura material contida nos relatos orais dos cidadãos, principalmente, dos idosos. Em sentido à avaliação das atividades de ensino, de campo e da produção científica, 
PET-Programa de educação tutorial: estrutura e ações nas cidades de São Raimundo Nonato-PI, Juazeiro-BA e petrolina-PE

optou-se por estimar os resultados a partir do diálogo com/entre os petianos. Com isso, existiu o estimulo à reflexão, desenvolvendo-se, igualmente, o sentido crítico e de responsabilidade dos discentes.

\section{RESULTADOS}

\section{Ensino}

Semanalmente a equipe se uniu para o delineamento de questões administrativas do planejamento, bem como à avaliação das atividades de pesquisa e extensão. Por meio de seminários temáticos, conduzidos pelo tutor, atingiu-se o aperfeiçoamento dos conhecimentos dos petianos. Uma importante ação no âmbito do ensino incidiu na instauração, no Campus UNIVASF de São Raimundo Nonato, da cerimônia de recepção dos alunos calouros do Curso de Arqueologia e Preservação Patrimonial. Os eventos contaram com a apresentação de slides sobre o Campus, sendo assim, os estudantes foram informados sobre particularidades dos parques nacionais da região Sudeste do Piauí, bem como sobre as áreas de atuação profissional do arqueólogo.

\section{Extensão}

Considerando que as pesquisas arqueológicas no Parque Nacional Serra da Capivara, o qual foi declarado pela UNESCO, em 1991, como patrimônio da humanidade já se encontram consolidadas para os períodos pré-coloniais, o grupo executou o projeto "Escavando História: São Raimundo Nonato além dos 100 anos”. Esse trabalho contemplou, de forma inovadora, uma lacuna científica da Arqueologia Histórica na região, visto que valorizou a comunidade local, tornando-a parte ativa do projeto. A técnica incidiu em convidar/estimular os membros da coletividade a atuarem no processo de construção da história de São Raimundo Nonato. A ação fortaleceu as metas do Projeto Pedagógico e Institucional da UNIVASF, pois promoveu a interiorização do conhecimento. De forma geral, o trabalho desenvolvido pelo grupo tem divulgado e consolidado, na região, princípios de responsabilidade social, orientados por valores básicos como o exercício da democracia, da justiça, da solidariedade, bem como o respeito à diversidade.

\section{Pesquisa}

No período de 2011 e 2013, o grupo participou do XVI-Congresso da Sociedade de Arqueologia Brasileira (SAB), realizado na cidade de Florianópolis-SC. Também apresentou 
PET-Programa de educação tutorial: estrutura e ações nas cidades de São Raimundo Nonato-PI, Juazeiro-BA e petrolina-PE

trabalhos na IV, V e VI Semanas de Ensino, Pesquisa e Extensão da UNIVASF, realizadas em Juazeiro-BA; além de organizar a exposição "Escavando História: São Raimundo Nonato além dos cem anos", no pátio central da Universidade Estadual do Piauí-UESPI. Nesse momento, artefatos e fotografias referentes à "Guerra da Telha" foram apresentados à comunidade local (Figura 1).

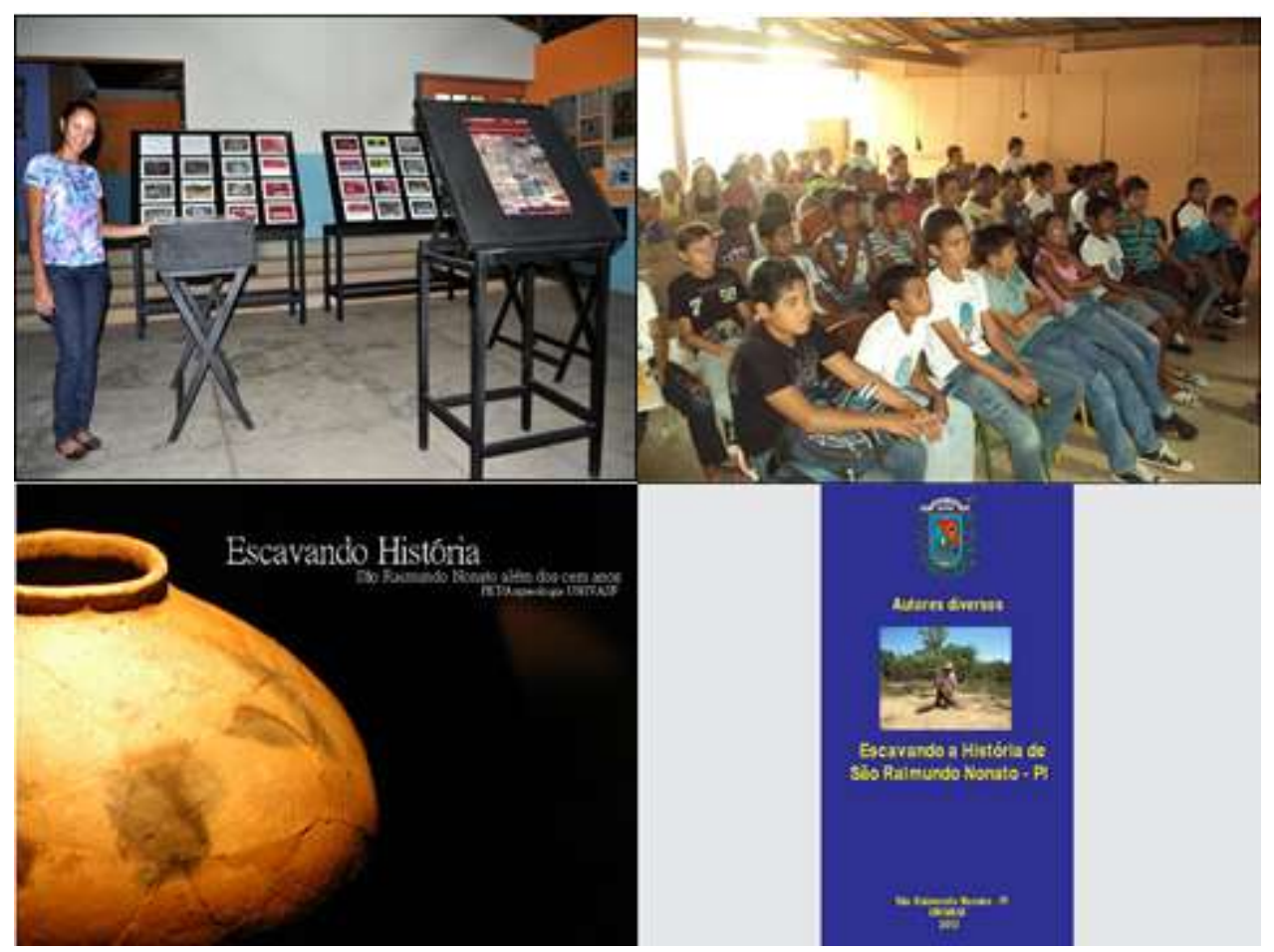

Figura 1. Ações do Programa de Educação Tutorial (PET-Arqueologia) Fonte: Elaborado pelos autores, 2015.

Valendo-se ainda das monografias produzidas pelos bolsistas e dos trabalhos escritos por alunos do curso de História da Universidade Estadual do Piauí (UESPI) foi publicado, em 2013, o livro "Escavando a História de São Raimundo Nonato-PI". Outro material desenvolvido e, posteriormente, distribuído em escolas da rede pública e particular da região foi a cartilha "Escavando História: São Raimundo Nonato além dos cem anos" (Figura 1).

\section{PET-BIOMECÂNICA}

A Filosofia de trabalho deste PET incide em estimular escolares do Ensino Fundamental I e II à adoção de hábitos posturais corretos. Assim, considerando a probabilidade de que deformações da estrutura musculoesquelética surgem nos anos elementares da educação escolar 
PET-Programa de educação tutorial: estrutura e ações nas cidades de São Raimundo Nonato-PI, Juazeiro-BA e petrolina-PE

(CANDOTTI; NOL; ROTH, 2012), o PET-Biomecânica desenvolve atividades teóricas e práticas, levando aos alunos informações úteis à prevenção de problemas de saúde. Outro ponto focal deste PET incide na conscientização de pais e professores sobre os perigos, futuros, à saúde dos escolares, quando cargas excessivas são transportadas na mochila escolar (KNOPLICH, 1985). Segundo Xavier et al. (2011), 80\% dos problemas posturais manifestados pela população adulta têm origem na infância, escalando durante a adolescência. Diante disso, o PETBiomecânica privilegia a disseminação de informações como: i) o melhor tipo de mochila a ser usado; ii) o peso ideal do material escolar a ser transportado na mochila, o qual não deve exceder a 10\% do peso corporal da criança; e, ii) o tipo do mobiliário oferecido pelas escolas (PENHA et al., 2008). Os objetivos desse grupo são:

I) conscientizar alunos do Ensino Fundamental I-II, professores e pais sobre a importância da adoção da boa postura corporal e a prática regular do exercício físico;

II) registrar o tipo de mochila utilizado por escolares, assim como divulgar a forma correta do seu transporte;

III) verificar o mobiliário das escolas, segundo questões ergonômicas, sugerindo medidas à adequação correta;

IV) avaliar a postura ortostática dos escolares, com referência no alinhamento das estruturas esqueléticas;

V) planejar, executar e avaliar programas de exercícios físicos para escolares;

VI) desenvolver princípios de competências social nos bolsistas e voluntários do PETBiomecânica;

VII- estimular os petianos tanto à produção de TCCS e artigos com foco na Postura Corporal de escolares, como a participar em eventos científicos.

\section{PROCEDIMENTOS METODOLÓGICOS}

As atividades do PET-Biomecânica são desenvolvidas no âmbito do Ensino, da Pesquisa e da Extensão. A partir da experiência acumulada no dia a dia, o grupo identificou/aprendeu que não existia um único método para o desenvolvimento das atividades, porém sim diferentes ferramentas para uma dada situação. Além de que todas permitiriam o alcance de fins comuns. Da mesma forma, a experiência do cotidiano mostrou que materiais e métodos já conhecidos devem ser adequados as novas situações. Nesse contexto, as ações da equipe incidiram no desenvolvimento de ciclos de palestras, na pesagem de mochilas, seguido da elaboração e envio de relatórios sobre o peso/sobrepeso das mochilas aos pais. Com a finalidade de avaliar hábitos 
PET-Programa de educação tutorial: estrutura e ações nas cidades de São Raimundo Nonato-PI, Juazeiro-BA e petrolina-PE

posturais e a percepção de dor nas costas dos escolares, um questionário foi aplicado. As ações do PET-Biomecânica também valorizaram a prática da atividade física. Sendo assim, planejou-se e se executou, duas vezes por semana, um conjunto de exercícios físicos, com 100 alunos, em idade entre 8-12 anos, de uma escola municipal da cidade de Petrolina-PE. A seguir três procedimentos metodológicos adotados pelo PET-Biomecânica serão apresentados:

I- Pesagem das mochilas e massa corporal dos escolares

A pesagem da mochila foi realizada por meio de uma balança analógica com capacidade máx. $15 \mathrm{~kg}$, resolução de $0,025 \mathrm{~kg}$. Já a massa corporal foi determinada por uma balança digital WISO - com 0,1 kg de resolução e capacidade máx. de $150 \mathrm{~kg}$. A análise dos dados se estabeleceu pela equação Prelativo $=\frac{m \text { material } \mathrm{X} \text { X } 100}{m \text { corporal } \mathrm{X} g}$. Dessa forma, identificou-se, se a mochila do aluno estava ou não em condições ideias para o transporte (volume $\leq$ a $10 \%$ do peso corporal).

II- Avaliação da percepção da postura corporal, dor nas costas, e transporte do material escolar.

A avaliação da percepção corporal foi realizada por meio do Instrumento de Avaliação da Postura Corporal e Dor nas Costas “BackPEl” (NOLL et al., 2013). Este questionário permite a avaliação da postura corporal de forma associada. Ele é composto por 21 perguntas, distribuídas em quatro dimensões: a) levantamento de dados demográficos; b) análise de fatores de riscos, por intermédio de imagens, indicando comprometimentos da postura dos escolares; c) informações sobre problemas posturais junto à familiares; e, d) levantamento de dados sobre a frequência da dor nas costas.

\section{III- Avaliação de desvios posturais (fotogrametria)}

Por meio da técnica da "Fotogometria", realizou-se o registro fotográfico de escolares nas vistas anterior, posterior e lateral (SANTOS et al., 2009; SACCO et al., 2007). Para tanto foram posicionados marcadores reflexivos esféricos nos seguintes pontos do corpo: mento, glabela, lóbulo das orelhas, acrômios, trocânteres maiores e a linha articular dos joelhos, ângulo inferior das escápulas, espinhas ilíacas ântero-superiores, espinhas ilíacas póstero-superiores, tendões calcâneos, calcâneos, maléolos laterais, centro das patelas e tuberosidade da tíbia.

As ações do PET-Biomecânica são autorizadas pela Secretaria Municipal de Educação de Petrolina-PE e foram aprovadas junto ao Comitê de Ética da Univasf (protocolo 0013/270812). 
PET-Programa de educação tutorial: estrutura e ações nas cidades de São Raimundo Nonato-PI, Juazeiro-BA e petrolina-PE

Assim sendo, a participação dos escolares nas atividades é antecedida pela assinatura do Termo de Consentimento Livre Esclarecido pelos pais e/ou responsáveis.

\section{RESULTADOS}

\section{Ensino}

Semanalmente, durante duas horas, existiu o encontro da equipe para discutir questões administrativas e planejar as atividades de extensão. Desse modo, foi instituído um grupo de estudo. Os momentos também foram direcionados à capacitação discente, realizada por seminários, ministrados pelo tutor e pelos próprios acadêmicos de Educação Física. As atividades contaram ainda com a participação de professores convidados, provindos de áreas distintas do conhecimento. Considerando que a vivência prática é fundamental à formação do profissional de Educação Física, as atividades teóricas privilegiaram a associação com técnicas e exercícios práticos.

\section{Extensão}

De acordo com Geldhof et al. (2007), no âmbito da educação postural, ações preventivas apresentam boa repercussão à melhora da postura corporal. Diante disso, o grupo desenvolveu, duas vezes por semana, durante 50 minutos, com quatro (4) turmas do $2^{\circ}$ e $5^{\circ}$ ano (100 alunos) exercícios específicos para o aperfeiçoamento da flexibilidade, alongamento, força, equilíbrio, agilidade e coordenação motora (Figura 2). Outra atividade extensionista incidiu no desenvolvimento de ciclos de palestras em diferentes escolas da rede Municipal local. As palestras foram montadas de acordo com a faixa etária dos escolares (6 - 8 anos e $9-12$ anos), contendo duração entre 20-30 minutos, abrangendo os seguintes tópicos: a) orientações sobre uso da mochila (carga, tipo e modo de transporte); b) diálogo com os professores; e, c) vivência prática de exercícios físicos (Figura 2). 
PET-Programa de educação tutorial: estrutura e ações nas cidades de São Raimundo Nonato-PI, Juazeiro-BA e petrolina-PE

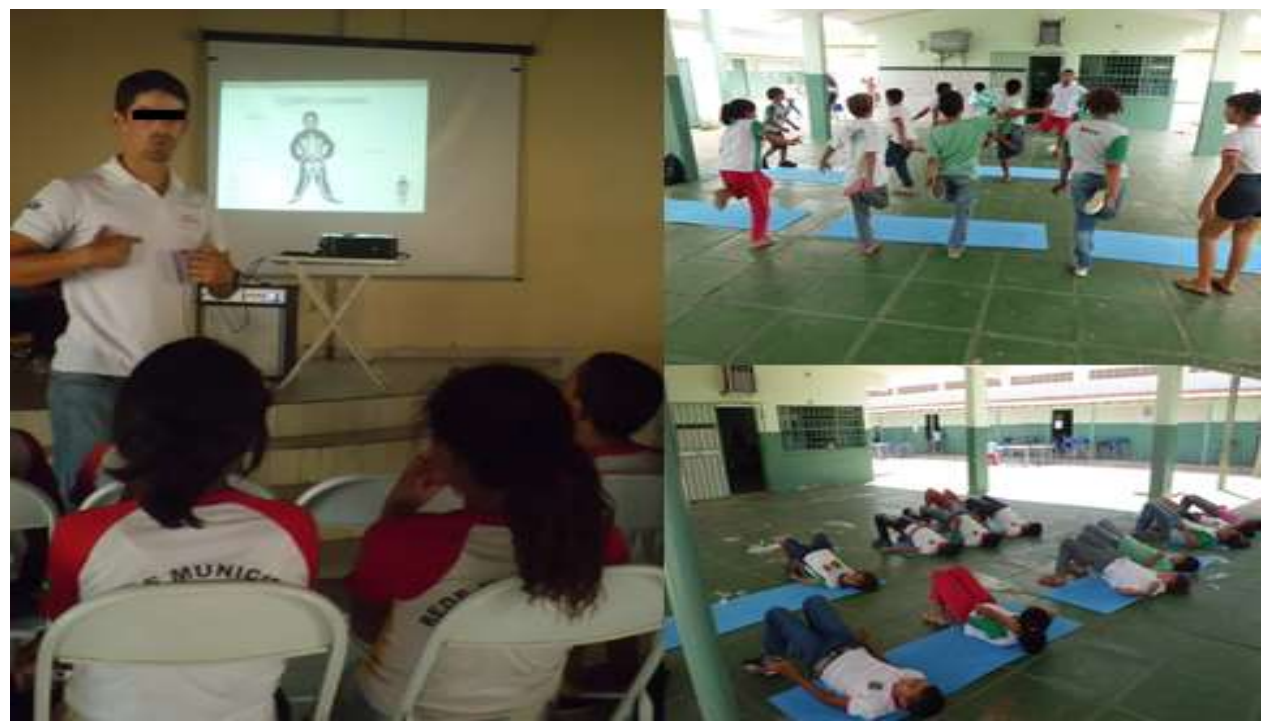

Figura 2 - Ações do Programa de Educação Tutorial (PET-Biomecânica) Fonte: Elaborado pelos autores, 2015.

\section{Pesquisa}

Desde 2011, os petianos vêm participando ativamente de encontros na área da Educação Física e Interdisciplinar, a nível regional e nacional. Nesse sentido, pode-se destacar o "XIVCongresso de Ciências do Desporto e Educação Física dos Países de Língua PortuguesaPALOPS" (Belo Horizonte); o II, III e IV Congresso de Educação Física do Vale do São Francisco-CEFIVASF (Juazeiro-BA/Petrolina-PE); e nas Jornadas Científicas da UNIVASF (2011-2013). Em seus três anos de açãos, o PET-Biomecânica também inspirou cinco bolsistas a escreverem Trabalhos de Conclusão de Curso (TCC), todos com foco na postura corporal de escolares da região.

Informações sobre o PET-Biomecânica podem ser acessadas, nos seguintes endereços: https://www.facebook.com/Pet-BiomecC3\%A2nica-569955173107075/ ?ref=hl; http://petunivasf.wix.com/biomecanica.

\section{PET-EDUCAÇÃO FÍSICA}

O PET-Educação Física teve sua gênese com o "Programa Educação para a Saúde e Lazer Ativo Orientado: Prevenção e Tratamento de Doenças Psicossociais e Cardiometabólicas na Comunidade de Petrolina/PE". A demanda surgiu a partir do estudo de Wagner et al. (2002) e Tsushita et al. (2003), os quais ratificaram a importância da orientação educacional para a melhoria 
PET-Programa de educação tutorial: estrutura e ações nas cidades de São Raimundo Nonato-PI, Juazeiro-BA e petrolina-PE

da saúde e qualidade de vida de indivíduos com problemas de ordem cardiometabólica, tais como: a obesidade, o diabetes mellitus e a hipertensão arterial sistêmica.

O impacto desses fatores de risco, associados à obesidade e à falta de atividade física podem desencadear complicações psicossociais (MUST; STRAUSS, 1999), além de desenvolverem igualmente a depressão (ANTON et al., 2006). A partir disso, observou-se a importância de agregar tanto conhecimentos, como profissionais de diferentes áreas para o tratamento dessas temáticas. Diante disso, este PET vem apostando - cada vez mais - na perspectiva interdisciplinar. Seus objetivos são:

I) Formar e informar, em sentido técnico-científico, crítico, pessoal e social discentes de cursos da área da saúde da UNIVVASF;

II) Promover a inclusão social, educacional, assim como ampliar os níveis de saúde dos frequentadores do Parque Municipal Josefa Coelho, situado na cidade de Petrolina-PE;

III) Diagnosticar a aptidão física de escolares da rede de ensino da cidade de Petrolina-PE;

IV) Incentivar seus integrantes à produção de trabalhos científicos na área da educação para a saúde, da atividade física orientada e da prevenção e controle de doenças crônico-nãotransmissíveis.

\section{PROCEDIMENTOS METODOLÓGICOS}

O grupo conta com estudantes de Educação Física, Farmácia, Psicologia, Medicina e Enfermagem. Seus procedimentos metodológicos integram experiências e conhecimentos de forma participativa e inovadora. O contato direto com a comunidade é realizado, diariamente, por meio da assistência aos frequentadores de um parque da cidade de Petrolina-PE. O grupo também desenvolve avaliações metabólicas e cardiométricas no laboratório de Fisiologia do Exercício, no Colegiado de Educação Física.

\section{RESULTADOS}

\section{Ensino}

No âmbito do Ensino são desenvolvidas reuniões, semanais, organizas sob a forma de grupo de estudo. Essas também servem como momento destinado à capacitação discente, coordenadas pelo tutor, contando ainda com a participação de professores convidados. O método eleito para o procedimento das atividades de ensino foi o de seminários. O Quadro 1 apresenta um resumo das principais ações desenvolvidas no período 2011-2013: 
PET-Programa de educação tutorial: estrutura e ações nas cidades de São Raimundo Nonato-PI, Juazeiro-BA e petrolina-PE

\begin{tabular}{|c|c|c|}
\hline Ano & Seminários Dirigidos & Capacitações Práticas \\
\hline 2011 & $\begin{array}{l}\text { - Projeto PET-Educação Física; } \\
\text { - Triagem e estratificação do risco; } \\
\text { - Dose do exercício físico para a } \\
\text { saúde; } \\
\text { - Exercício na prevenção de doenças; } \\
\text { - Classificação da aptidão física } \\
\text { funcional; } \\
\text { - Apresentação de projetos de } \\
\text { pesquisa, }\end{array}$ & $\begin{array}{l}\text { - Avaliação da composição corporal; } \\
\text { - Avaliação do desempenho motor; } \\
\text { - Avaliação da pressão arterial e frequência } \\
\text { cardíaca; } \\
\text { - Medidas de glicemia, colesterol e } \\
\text { triglicerídeos; } \\
\text { - Noções sobre estatística descritiva, }\end{array}$ \\
\hline 2012 & $\begin{array}{l}\text { - Exercício na prevenção do estresse } \\
\text { ansiedade e depressão; } \\
\text { - Atividade física e hipertensão arterial; } \\
\text { - Atividade física e diabetes melittus; } \\
\text { - Aspectos motivacionais na prática da } \\
\text { atividade física; } \\
\text { - Apresentação de projetos de } \\
\text { pesquisa. }\end{array}$ & $\begin{array}{l}\text { - Avaliação dos níveis de atividade física; } \\
\text { - Treinamento para avaliação dos níveis de } \\
\text { qualidade de vida na população; } \\
\text { - Avaliação dos níveis de estresse, } \\
\text { ansiedade e depressão na comunidade; } \\
\text { - Reavaliação antropométrica e motora; } \\
\text { - Noções sobre estatística inferencial. }\end{array}$ \\
\hline 2013 & $\begin{array}{l}\text { - Função autonômica cardíaca e } \\
\text { exercício; } \\
\text { - Monitoração ambulatorial da pressão } \\
\text { arterial (24h) e exercício físico; } \\
\text { - Monitoração ambulatorial da } \\
\text { glicemia (24h) e exercício físico; } \\
\text { - Desempenho motor em escolares; } \\
\text { - Apresentação de projetos de } \\
\text { pesquisa, }\end{array}$ & $\begin{array}{l}\text { - Treinamento para avaliação da } \\
\text { monitoração ambulatorial da pressão } \\
\text { arterial (MAPA); } \\
\text { - Treinamento para avaliação da função } \\
\text { autonômica cardíaca; } \\
\text { - Treinamento para avaliação da capacidade } \\
\text { energética e aptidão aeróbia; } \\
\text { - Noções sobre estatística descritiva e } \\
\text { inferencial. }\end{array}$ \\
\hline
\end{tabular}

\section{Extensão}

O grupo PET-Educação Física possui base extensionista no Parque Municipal Josefa Coelho, localizado na cidade de Petrolina-PE. As ações do período 2011-2013 consistiram na orientação da prática da atividade física, em associação com a divulgação de hábitos saudáveis de vida. Diariamente, foram atendidos no parque, aproximadamente 150 indivíduos adultos, predominando os cidadãos idosos (60-80 anos). Outra importante ação do PET-Educação Física com a comunidade petrolinense tem sido o evento anual, denominado como "Sábado Saudável: Cuidar para Bem-Estar". O Quadro 2 apresenta um resumo das atividades extensionistas do grupo: 
PET-Programa de educação tutorial: estrutura e ações nas cidades de São Raimundo Nonato-PI, Juazeiro-BA e petrolina-PE

\begin{tabular}{|c|c|c|}
\hline \multicolumn{3}{|c|}{$\begin{array}{l}\text { 1. Atendimento ao público no Parque Municipal Josefa } \\
\text { Coelho/Petrolina-PE }\end{array}$} \\
\hline Segunda a Sexta & 06:00h às 08:30h & 16:00h às $18: 30 \mathrm{~h}$ \\
\hline População & Média $60-80$ pessoas & Média $50-70$ \\
\hline \multicolumn{3}{|c|}{ 2. Evento anual: “Sábado Saudável: Cuidar para bem-estar” } \\
\hline Edição / Data & Equipe de trabalho & População atendida \\
\hline $\mathrm{I}-05 / 11 / 2011$ & 12 bolsistas +13 voluntários & 299 participantes \\
\hline II $-15 / 09 / 2012$ & 12 bolsistas +18 voluntários & \\
\hline III $-14 / 09 / 2013$ & 12 bolsistas +18 voluntários & 427 participantes \\
\hline
\end{tabular}

Quadro 2 - Atividades de Extensão do PET-Educação Física (2011-2013)

Fonte: Elaborado pelos autores, 2015.

O evento "Sábado Saudável: Cuidar para bem-estar" permitiu o enraizamento dos petianos com a comunidade. Paralelamente, observou-se que por meio dele pessoas que, até então, não frequentam o parque, aderiram à atividade física regular e orientada. As atividades desse evento foram distribuídas em oito setores: 1) avaliação antropométrica; 2) avaliação da flexibilidade; 3) avaliação hemodinâmica (pressão arterial); 4) avaliação metabólica (glicemia); 5) avaliação da qualidade de vida e nível de atividade física; 6) orientação nutricional; 7) miniaulas de Yoga, Pilates, alongamento e dança; 8) "Sabadinho saudável”, composto por atividades recreativas voltadas ao público infantil (Figura 3):

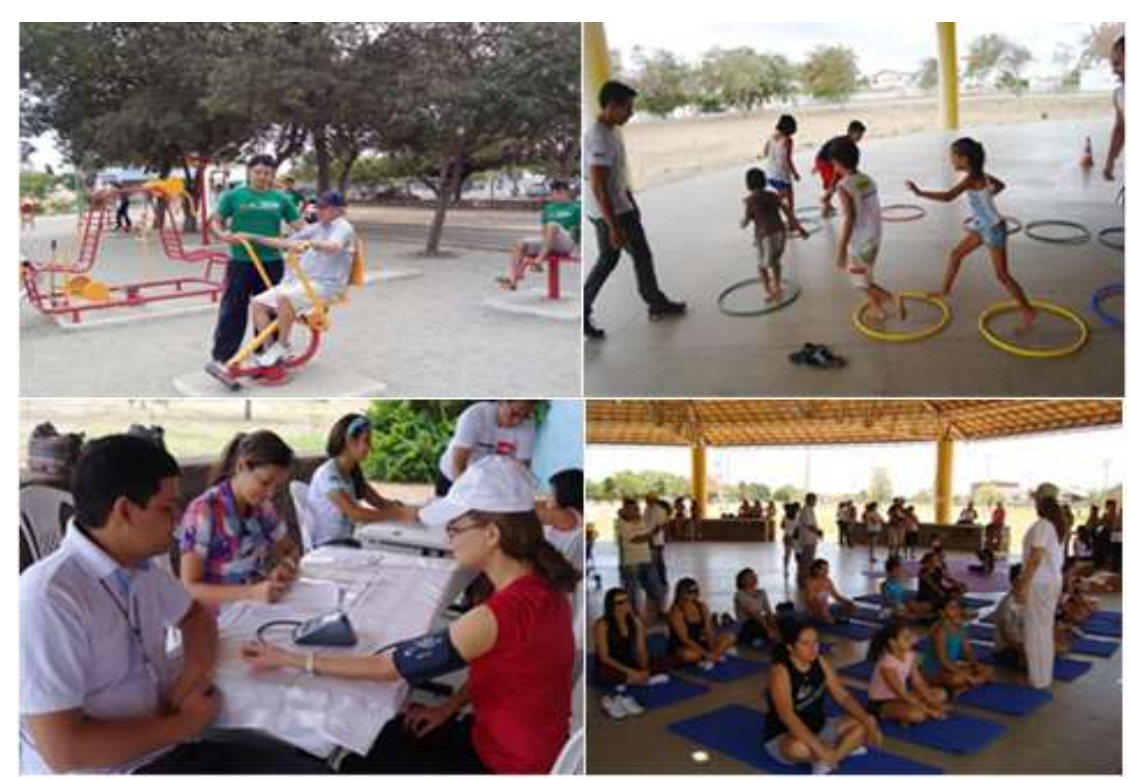

Figura 3 - Atividades do Programa de Educação Tutorial (PET-Educação Física) Fonte: Elaborado pelos autores, 2015.

\section{Pesquisa}


PET-Programa de educação tutorial: estrutura e ações nas cidades de São Raimundo Nonato-PI, Juazeiro-BA e petrolina-PE

No âmbito da Pesquisa o grupo vem desenvolvendo diferentes projetos, todos com ascendência nas atividades extensionistas. Os trabalhos desenvolvidos apresentam o caráter interdisciplinar, contando com a participação de alunos dos cursos da área da saúde da UNIVASF. Ao longo triênio 2011-2013, as produções científicas do grupo se estenderam entre congressos e seminários, como: “36 Simpósio Internacional de Ciências do Esporte”, em São Paulo; "IV Congresso Brasileiro de Metabolismo, Nutrição e Exercício", em Londrina; "28 Congresso Internacional de Educação Física - FIEP”, em Foz do Iguaçu. Internacionalmente, existiu em 2012 e 2013 a publicação online de artigos no "Joumal of Exercise Physiology", determinando o reconhecimento do trabalho deste PET.

Informações, bem como o contato do PET-Educação Física estão disponíveis no site: http://www.peteducacaofisica.com/home.html.

\section{PET- CONEXÃO DE SABERES: SANEAMENTO AMBIENTAL}

O programa "Conexões de Saberes: Saneamento Ambiental" tem como objetivo o empoderamento de cidadãos da comunidade da cidade de Juazeiro-BA sobre demandas locais na área do Saneamento Básico e do Meio Ambiente. Isso significa dizer que suas ações buscam a valorização e o uso adequado dos serviços de saneamento básico a partir de medidas educativas na área sanitária e ambiental. Ao longo de seus três anos, o programa motivou transformações significativas junto à percepção de moradores de bairros populares. Assim, mediante a conscientização popular, a importância do saneamento básico a nível social foi evidenciada, como consequência disso existiu o entendimento - gradativo - da população sobre as causas dos problemas. Prontamente, as ações do PET vêm reforçando a consciência da população à preservação ambiental, além de ampliar os níveis de sua saúde, bem-estar, qualidade de vida e responsabilidade social da comunidade juazeirense.

No ambiente acadêmico o programa tem potencializado o envolvimento de estudantes de origem popular, em geral, oriundos dos cursos de Engenharia Agrícola e Ambiental, Engenharia Civil e Engenharia de Produção em ações de Ensino, Pesquisa e Extensão. Dessa forma, o programa estimulou a aprendizagem de demandas ambientais locais por meio da vivência, em tempo real, de forma reflexiva e discursiva.

\section{PROCEDIMENTOS METODOLÓGICOS}


PET-Programa de educação tutorial: estrutura e ações nas cidades de São Raimundo Nonato-PI, Juazeiro-BA e petrolina-PE

Como os demais grupos PET da Universidade Federal do Vale do São Francisco, esta equipe trabalha de forma concomitantemente as atividades de Ensino, Pesquisa e Extensão. Seus métodos adotam o estudo dirigido, a apresentação de trabalhos, bem como a aplicação de questionários e entrevistas junto à comunidade. Tais artifícios são direcionados para o diagnóstico da realidade do saneamento básico local, assim como da forma como seus atores percebem isso em seus bairros. Mediante o estudo da percepção das pessoas o grupo identificou as demandas dos espaços, bem como o conhecimento dos cidadãos. Atributos dessa ordem fundamentaram as ações deste PET, o qual vem investindo no empoderamento da comunidade por meio de medidas educativas (VALOURA, 2006; VASCONCELOS, 2001). Ademais suas ações buscam contemplar as comunidades beneficiadas pelo Programa de Aceleração do Crescimento (PAC),o qual é desenvolvido pelo Governo Federal, em parceria com a Prefeitura Municipal de Juazeiro (PMJ, 2011).

\section{RESULTADOS}

\section{Ensino}

As ações foram desenvolvidas sob a forma de grupo de estudos. Os momentos foram dedicados ao planejamento, à organização e à avaliação das atividades de Pesquisa e Extensão. Assim, sob a orientação da tutora, o grupo aprendeu a discutir temáticas pertinentes da área, buscando formas adequadas para intervir junto à comunidade. Pode-se dizer que a base metodológica deste PET apresenta princípios fenomenológicos, visto que a partir da reflexão do "eu" no e com o seu ambiente/outro busca transformar hábitos de vida; algo intrínseco à percepção e ao juízo, logo importante à formação a consciência sustentável dos cidadãos juazeirenses. Sendo assim, apostou-se na aprendizagem a partir de experiências novas e interessantes. Durante os encontros formativos, uma modo encontrado para o aperfeiçoamento de aprender foi obtido por meio dos "Seminários Temáticos", apresentados pelos próprios bolsistas (Figura 4). Os temas abordados focalizaram problemas centrais da área do Meio Ambiente, da Sustentabilidade e do Saneamento Básico local.

\section{Extensão}

Partindo do entendimento de que para se atingir uma Educação Ambiental, com sucesso, necessita-se de medidas permanentes de aprendizagem, moldadas na valorização de conhecimentos subjetivos da pessoa, o grupo desenvolveu, entre 2011-2013, ciclos de palestras e 
PET-Programa de educação tutorial: estrutura e ações nas cidades de São Raimundo Nonato-PI, Juazeiro-BA e petrolina-PE

oficinas para os professores de escolas da rede pública de Juazeiro-BA. Esses eventos também foram estendidos para os agentes e líderes comunitários de saúde. Dessa froma, foi possível capacitar essas pessoas, tornando-os agentes multiplicadores de conhecimentos próprios da área do PET, na região.

Durante o processo de estruturação e avaliação das atividades, o grupo se preocupou em criar situações que tivessem - realmente - pontos de intersecção entre a temática tratada e a população alvo. Nesse sentido, as atividades de Pesquisa, Estudo e Extensão teceram redes, as quais foram fundamentais para o tratamento do Saneamento Básico com qualidade. Aliado a isso, o PET solicitou a participação dos moradores (associações de bairros) junto ao processo de conservação do sistema de água e esgoto local, utilizando, por exemplo, "eco kits" como instrumento à aprendizagem; além de oferecer, em caráter teórico e prático, cursos sobre a qualidade da água para o consumo (Figura 4).

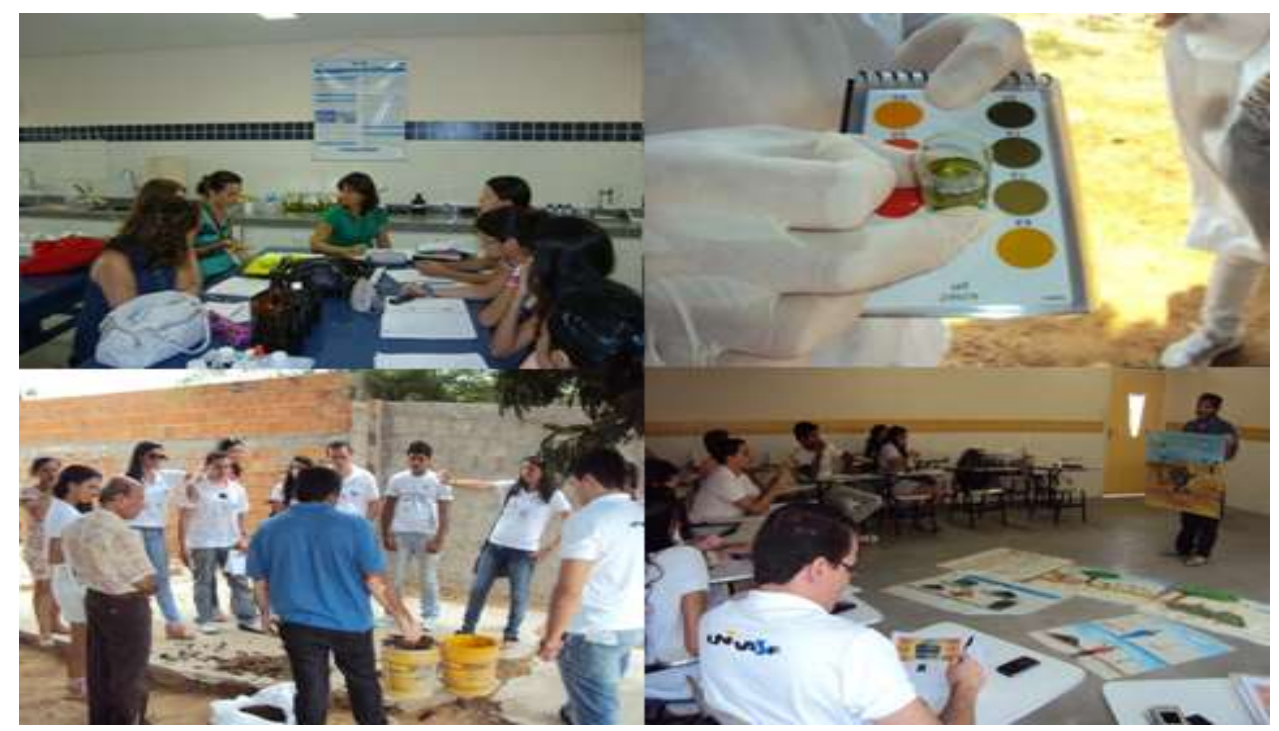

Figura 4 - Ações do Programa de Educação Tutorial (PET-Conexão de Saberes: Saneamento Ambiental) Fonte: Elaborado pelos autores, 2015.

Outro momento significativo do trabalho consistiu em uma Exposição Fotográfica, intitulada como: O Despertar do Olhar sobre a Realidade do Saneamento Básico/Ambiental. Essa exposição surtiu efeito sobre a forma como a comunidade enxergava a realidade do saneamento básico local. As fotografias apresentadas foram obtidas durante os trabalhos de Pesquisa e Extensão, desenvolvidos sob a proposta de empoderamento das comunidades de Juazeiro-BA. Com base na técnica de documentação visual, produziu-se um vídeo-documentário (90 minutos). Este abordou o tema Saneamento Básico, trazendo definições e imagens de 
PET-Programa de educação tutorial: estrutura e ações nas cidades de São Raimundo Nonato-PI, Juazeiro-BA e petrolina-PE

estações de água de tratamento de esgoto, integrando imagens sobre o trabalho dos bolsistas em suas ações de saneamento ambiental e educação sanitária nas comunidades.

Em 2012 foi realizado "I Encontro do Vale do São Francisco sobre Saneamento Básico/Ambiental \& I Mostra do Programa de Educação Tutorial - PET Conexões de Saberes: Saneamento Ambiental" (Figura 4). Nesse momento, foram ofertadas oficinas e palestras sobre compostagem, além de cursos sobre a qualidade da água. O público integrante foi composto por cidadãos da comunidade, alunos, docentes e técnicos UNIVASF; além de integrantes das demais IES da região. Esta ação foi desenvolvida, conjuntamente, com grupos comunitários: professores, alunos da rede municipal, líderes comunitários, agentes de saúde e trabalhadores do Mercado Produtor de Juazeiro.

Como principal resultado das atividades de extensão se salienta os conhecimentos repassados durante os encontros de Saneamento Básico, os quais repercutiram a sensibilização dos envolvidos. Percebeu-se que isso estimulou os envolvidos à criação e manutenção de relacionamentos mais solidários com as questões ambientais locais. Da mesma forma, as ações contribuíram à formação de multiplicadores de conhecimentos próprios da temática em questão. Sendo assim, promoveu-se o desenvolvimento sustentável.

\section{Pesquisa}

O tema foco da investigação do grupo residiu no diagnóstico do Saneamento Básico de bairros da cidade de Juazeiro-BA. Assim sendo, foram elaboradas planilhas para a coleta de indicadores relativos ao tratamento da água, do esgotamento sanitário, da limpeza pública, dos resíduos sólidos e da drenagem de águas pluviais. A partir disso, partiu-se para o trabalho de campo, verificação "in loco". Os dados colhidos foram tabulados em planilha EXCEL, seguido de análise estatística básica descritiva.

Constatou-se que as condições de Saneamento Básico dos Bairros de Juazeiro-BA são claramente divergentes. Pois, enquanto haviam bairros com ambientes urbanos agradáveis e organizados, a exemplo do Centenário e Maria Gorethe, haviam outros como o Jardim Flórida e Piranga que apresentavam graves problemas de saneamento básico, com esgotos a céu aberto e falta de pavimentação; além de problemas com áreas alagadas.

Em sentido à produção científica, em seus três anos de existência, o grupo apresentou 16 artigos em Congressos nacionais e internacionais. Também produziu cinco TCCS, todos com ênfase na cidade de Juazeiro-BA, abordando os seguintes temas: Coleta e disposição final de resíduos sólidos; Resíduos Sólidos Agroindustriais; Percepção e Empoderamento; e, Infraestrutura e percepção acerca do saneamento básico. 
PET-Programa de educação tutorial: estrutura e ações nas cidades de São Raimundo Nonato-PI, Juazeiro-BA e petrolina-PE

Informações sobre o PET-Conexões de Saberes: Saneamento Ambiental estão nos sites: http://www.univasf.edu.br/ petsaneamento/; petambientalunivasf.blogspot.com.

\section{CONSIDERAÇÕES FINAIS}

Uma das missões institucionais da Universidade Federal do Vale do São Francisco incide na promoção da interiorização do conhecimento na região do Sertão nordestino, corrigindo e/ou amenizando desigualdades. Nessa perspectiva, os grupos PET construíram, entre 2011-2013, por meio da indissociabilidade entre a Extensão, a Pesquisa e o Ensino mecanismos à congruência do saber acadêmico com o popular, processados no ir e vir de informações com as comunidades, onde operam. Ademais, seus serviços vêm consubstanciando, em três Estados da União, uma via de mão dupla que possibilitou a democratização de conhecimentos que, até então, permaneciam em sala de aula. Sendo assim, as atividades dos grupos configuraram uma das metas do Plano Nacional de Extensão (BRASIL, 2007), o qual busca a disseminação do conhecimento acadêmico.

Conclui-se que a partir dos resultados obtidos pelas equipes foram atingidas transformações significativas junto a um grupo considerável de discentes dos respectivos cursos de graduação das quatro equipes do PET. Igualmente, foi possível a criação de mecanismo à conciliação do saber teórico ao prático de forma sui generis, incentivando e valorizando nos currículos dessas formações, cada vez mais, o aprender fazendo. Outro aspecto a salientar, incide no desenvolvimento da percepção da cidadania tanto dos petianos, como dos membros da comunidade; algo propiciado pelo contato/troca entre aluno-comunidade-demanda. Quanto às dificuldades, pode-se afirmar que elas ocorreram, porém na perspectiva petiana isso incidiu como mais um instrumento para o aprendizado. Nessa perspectiva, episódios como o tratamento com limitações próprias e/ou imprevistos da vida profissional diária foram essenciais para o exercício de capacidades sociais dos petianos.

Em sentido à comunidade, observou-se que seu empoderamento foi fundamental para o desenvolvimento de novos hábitos de vida consigo mesmo, com história local e meio ambiente. Isso significa dizer que as atividades dos grupos PET-UNIVASF propiciaram transformações significativas nas atitudes de vida tanto de crianças, como de jovens, adultos e idosos, em três estados da Federação. Paralelo a isso, os grupos PET têm contribuído para o reconhecimento da competência do trabalho extensionista que vem sendo desenvolvido pela Universidade Federal do Vale do São Francisco, na região do Semiárido Nordestino. 
PET-Programa de educação tutorial: estrutura e ações nas cidades de São Raimundo Nonato-PI, Juazeiro-BA e petrolina-PE

\section{APOIO E AGRADECIMENTOS}

Ministério da Educação e Cultura e Fundo Nacional de Desenvolvimento da Educação.

A todos os discentes da UNIVASF que atuam e/ou já participaram nas equipes PET, assim como, os membros das comunidades que participaram e ainda, hoje, apoiam nossas atividades.

\section{REFERÊNCIAS}

ANTON, S. D.; NEWTON Jr, R. L.; SOTHERN, M.; MARTIN, C. K.; STEWART, T. M.; WILLIAMSON, D. A. Association of depression with Body Mass Index, sedentary behavior, and maladaptive eating attitudes and behaviors in 11 to 13-year old children. Eating and Weight Disorders, Milano, v. 11, p. 102-108, 2006.

BRASIL. Lei no 10.473 de 27 de junho de 2002. Diário oficial da União. Brasília, DF, 27 de jun. 2002. Disponível em: http://imagem.camara.gov.br/Imagem/d/pdf/DCD15JUN2011.PDF. Acesso em: 18 abr. 2015.

CANDOTTI, C.T.; NOLL, M.; ROTH, E. Avaliação do peso e do modo de transporte do material escolar em alunos do Ensino Fundamental. Revista Paulista de Pediatria. São Paulo, v. 30 , n. 1, p. 100-106, 2012

GELDHOF, E.; CARDON, G.; DE BOURDEAUDHUIJ, I.; DE CLERCQ, D. Back posture education in elementary schoolchildren: a 2-year follow-up study. European Spine Journal, v. 16, n. 6, p. 841-50, 2007.

KNOPLICH, J. A coluna vertebral da criança e do adolescente. Ed. Panamed: São Paulo, 1985.

MEC/DEPEM. Programa de Educação Tutorial-PET. Manual de Orientações Básicas. Brasília, DF, dez. 2006.

MUST, A.; STRAUSS, R.S. Risks and consequences of childhood and adolescent obesity. International Journal of Obesity and Related Metabolic Disorders, Hampshire, v. 23, p. 211, 1999. 
PET-Programa de educação tutorial: estrutura e ações nas cidades de São Raimundo Nonato-PI, Juazeiro-BA e petrolina-PE

NOLL, M.; CANDOTTI,C.T.; TIGGEMANN,' C.L.; SCHOENELL M.C.V.; VIEIRA, A. Prevalência de hábitos posturais inadequados de escolares do Ensino Fundamental da cidade de Teutônia: um estudo de base populacional. Revista Brasileira de Ciência do Esporte, v.35, n.4, p. 983-1004, 2013.

PENHA, P.J.; CASSAROTO, R.A.; SACCO, I.C.N.; MARQUES, A.P. Qualitative postural analysis among boys and girls of seven to ten years old of age. Revista Brasileira de Fisioterapia. São Carlos, v. 12, n. 5, p. 386-391, 2008.

PREFEITURA MUNICIPAL DE JUAZEIRO-BA, Lei Orgânica do Município de JuazeiroBA, disponível em<http://www.juazeiro.ba.gov.br/arquivos/leg/lei organica do municipio.pdf $>$.Acesso em: 15 abr. 2015.

SACCO, I. C. N.; ALIBERT, S.; QUEIROZ, B. W. C.; PRIPAS, D.; KIELING, I.; KIMURA, A. A.; SELLMER, A. E.; MALVESTIO, R. A.; SERA, M. T. Confiabilidade da fotogrametria em relação à goniometria para avaliação postural de membros inferiores. Revista Brasileira de Fisioterapia, São Carlos, v. 11, n. 5, p. 411-417, 2007.

SANTOS, M. M.; SILVA, M. P. C.; SANADA, L. S.; ALVES, C. R. J. Análise postural fotogramétrica de crianças saudáveis de 7 a 10 anos: confiabilidade interexaminadores. Revista Brasileira de Fisioterapia, São Carlos, v. 13, n. 4, p. 350-355, 2009.

TSUSHITA, K.; HAYASE, S.; MATSUMOTO, K.; KATO, M.; YAMAMOTO, M.; SATO, Y. The effects of a practical diabetes prevention training course for public health care providers in Aichi Prefecture. Nippon Koshu Eisei Zasshi. Apr, v. 50, n. 4, p. 349-59, 2003.

VALOURA, L. C. Paulo Freire, o educador brasileiro autor do termo Empoderamento, em seu sentido transformador. Programa Comunicarte de Residência Social, 2005/2006.

VASCONCELOS, E. M., 2001. “A proposta de empoderamento e sua complexidade: uma revisão histórica na perspectiva do Serviço Social e da saúde mental” In: Revista Serviço Social \& Sociedade: seguridade social e cidadania. Ano XXII; 65:5-53.

XAVIER, C.A.; BIANCHI, D.M.; LIMA, A.P.; SILVA, I.L.; CARDOSO, F.; BERESFORD, H. Uma avaliação acerca da incidência de desvios posturais em escolares. Revista Meta: Avaliação. Rio de Janeiro, v. 3, n. 7, p. 81-94, 2011.

WAGNER, P.J.; JESTER, D.M.; MOSELEY GC. Medical students as health coaches. Academy Medical. Nov, v. 77, n. 11, p. 1164-5, 2002. 